\title{
Recruitment and Retention of Latino Adolescents to a Research Study: Lessons Learned from a Randomized Clinical Trial
}

Antonia M. Villarruel, Loretta S. Jemmott, John B. Jemmott, and Brenda L. Eakin

PURPOSE. To describe facilitators and barriers to participation and retention of Latino adolescents in a randomized clinical trial.

DESIGN AND METHODS. Participants were part of a randomized clinical trial designed to reduce HIV sexual risk behavior among Latino youth. Responses from 106 randomly selected respondents from the 3-month follow-up were content analyzed. RESULTS. Four main facilitator patterns emerged: peer/family support, program incentives, commitment, and desire to help. Participation barriers included conflicts with other commitments, embarrassment, and lack of peer support.

PRACTICE IMPLICATIONS. Recruitment and retention of Latino adolescents in research studies is critical to building a research base for nursing practice.

Search terms: HIV prevention, Latino adolescents, nursing, randomized controlled trial, recruitment, retention Accepted for publication April 5, 2006
Antonia M. Villarruel, PhD, FAAN, is Profesor, University of Michigan, School of Nursing, Ann Arbor, MI; Loretta S. Jemmott, PhD, FAAN, is Professor, University of Pennsylvania, School of Nursing, Philadelphia, PA; John B. Jemmott, III, PhD, is Professor, University of Pennsylvania, Annenberg School for Communications, Philadelphia, PA; and Brenda L. Eakin, MS, is Research Specialist, University of Michigan, School of Nursing, Ann Arbor, MI.

$\mathrm{R}$ participants requires significant effort (Lamb, Puskar, \& Tusaie-Mumford, 2001). Failure to retain the targeted number of participants prolongs the time required for the study, threatens internal and external validity, reduces statistical power, and drains scarce research resources (Davis, Broome, \& Cox, 2002). Specific populations may require targeted efforts to ensure adequate representation in clinical trials. In this paper, we describe facilitators and barriers to participation and retention of Latino adolescents in a randomized clinical trial.

Specific factors have been identified that affect the recruitment of minority adolescents into research studies (Levkoff, Prohaska, Weitzman, \& Ory, 2000); however, limited research is available concerning the retention of adolescent participants in randomized clinical trials. Retention has been associated with a variety of factors including participant age and developmental stage, ethnicity and gender, illness severity, patterns of healthcare utilization, ethical and legal guidelines, and access to school settings (Davis et al., 2002; Lamb et al., 2001). In a focus group study with African American children, Clark-Jones and Broome (2001) found that both adolescents who were well and those who were ill cited similar reasons for participation and continued engagement in a research project. Reasons for participation included increased knowledge about health conditions, expectations about research interventions, incentives, and logistical considerations (e.g., transportation, time, location, setting). Reasons for continued engagement in the project included the content of the intervention, characteristics of the instructor or clinician, 
having control or choices during the intervention, and their relationships with peers in the project.

\section{The recruitment and retention of Latinos}

\section{into clinical research studies calls for special}

\section{consideration of cultural factors. Few}

studies have been found that document

recruitment and retention strategies specific

\section{to Latinos, and in particular Latino}

\section{adolescents.}

Supportive relationships and parental involvement have also been reported as important considerations in the retention of adolescent research subjects. Activities that establish an environment supportive of health behaviors through teacher and parent involvement in the intervention and enhancing peer support for positive change were identified as effective recruitment and retention approaches for adolescent intervention research (Talashek, Norr, \& Dancy, 2003). In another study with chronically ill adolescents, Broome and Richards (2003) found that parents had a strong influence on adolescents' decisions to engage in research. These adolescents stated they had faith that parents would do what was best for them and would respect their wishes to participate or not participate. Other studies have focused on the initial recruitment of parents as a way to engage their adolescent children (Prado, Pantin, Schwartz, Lupei, \& Szapocznik, 2005).

The recruitment and retention of Latinos into clinical research studies calls for special consideration of cultural factors. Few studies have been found that document recruitment and retention strategies specific to Latinos, and in particular Latino adolescents.

Pletsch, Howe, and Tenney (1995) have argued for a two-tiered strategy that combines focused communitybased efforts and broad mass-media outreach. Furthermore, researchers have stressed the importance of incorporating cultural values such as familialism (family obligations), simpatia (respectful interaction), confianza (support and trust), and respeto (respect) in the recruitment and retention process (Keller, Gonzales, \& Fleuriet, 2005). The use of cultural insiders within their respective communities has also been shown to be effective in the retention of Latinos in research studies (McQuiston \& Flaskerud, 2003).

The purpose of this paper is to describe lessons learned in the recruitment and retention of Latino adolescents to a randomized clinical trial to test the efficacy of a behavioral intervention designed to reduce sexual risk behavior. We will provide a brief overview of the study, describe our recruitment and retention strategies, present data from adolescents enrolled in the study related to their perceptions of barriers and facilitators to participation, and discuss implications of findings for the retention of Latino adolescents in clinical trials.

\section{Study Overview}

Details of this study have previously been described (Villarruel, Jemmott, \& Jemmott, 2005). The purpose of this randomized controlled study was to test the efficacy of a culturally tailored behavioral intervention designed to reduce the HIV sexual risk behavior among Latino youth (Villarruel, Jemmott, \& Jemmott, 2006). The Human Subjects Committees of both the University of Pennsylvania and the University of Michigan approved this study. Latino students were recruited from local area high schools and community-based organizations to participate in " Cuidate! Latino Youth Health Promotion Program." The 8-hr program consisted of six 50-min modules and was conducted over two consecutive Saturdays. Students interested in the program 


\section{Recruitment and Retention of Latino Adolescents to a Research Study}

were provided with a cover letter. Prior to participation, students had to provide research staff with a signed parental consent form and written assent. All students completed questionnaires in either English or Spanish and were randomized into either the HIV risk-reduction group or the general health control group. Data were collected at pre-intervention, immediately postintervention, and at 3-, 6-, and 12-month follow-ups.

In this study, most students completed both the pre- and post-test training, with $96 \%$ completing the HIV risk-reduction intervention and $94 \%$ completing the general health promotion intervention. In addition, at the 3-month follow-up, $82 \%$ of students in the HIV risk-reduction group and $86 \%$ of those in the general health promotion intervention completed the data collection; at the 6-month follow-up, $81 \%$ of those in the HIV risk-reduction group and $85 \%$ in the general health promotion group completed the data collection; and at the 12-month follow-up, $80 \%$ of those in the HIV risk-reduction group and $84 \%$ in the general health promotion group completed the data collection. Of the students who did not complete all of the follow-up sessions, $4.3 \%(n=28)$ moved out of the city-primarily to New York or Puerto Rico-prior to the 3-month follow-up or were out of the country for an extended period of time. Only three students $(0.5 \%)$ indicated they no longer wished to participate. Sixty-three participants $(9.6 \%)$ failed to complete the program for unknown reasons. It was difficult to contact a number of participants because they were no longer living at the same residence, had no forwarding address, or the contact information they provided was invalid (i.e., no such address). Many participants also dropped out of the school system during the study period, making it difficult to locate them.

\section{Development of a Recruitment and Retention Infrastructure}

Considerable effort was directed toward the development of a recruitment and retention infrastructure. For example, the principal investigator had developed relationships with key leaders in the Latino community years prior to the implementation of the study. Many community leaders and their staff were involved in providing input into the design of the research study. At the community's request, interventions were also developed in Spanish in order to include Spanishdominant youth in the study. Community members felt this was an important but often ignored population of adolescents.

Input from community leaders indicated that schools would be an ideal location from which to recruit and also to conduct the interventions. In order not to interfere with scheduled school activities or curriculum, the intervention and follow-ups were conducted on Saturdays. Prior to starting the implementation of the study, information meetings were held with key school personnel, including the school superintendent, cluster leaders (persons who had administrative oversight for several schools in a geographic area), and principals. In these meetings we outlined the purpose and scope of the study, potential benefits to the school and its students, what was needed from the school to conduct the study, and perhaps more importantly, what was needed from the research team so as not to disrupt school activities.

Another important aspect to building a recruitment and retention infrastructure was ensuring that all materials and communication were culturally and linguistically appropriate. All study materials-questionnaires, registration slips, letters to parents and students, postcards, and consent forms were translated into Spanish. In addition, the principal investigator, project director, and recruitment and retention specialists were bilingual and bicultural. Facilitators and project assistants were recruited and hired from Latino, communitybased agencies and schools in which the interventions were held. Persons who worked on the project were an excellent source for recruiting adolescents-from their neighborhoods, families, and schools and community agencies in which they worked.

Recruitment. School personnel were helpful in identifying strategies and facilitating recruitment. For example, 
some schools invited us to familiarize students with the program by participating in school assemblies. Research team members were also invited to recruit students in the cafeteria during study hall and meal times. Another recruitment strategy, identified from school personnel, was offering students a community/ service credit for participating. This credit was necessary for graduation, and school personnel decided that participation in the program could fulfill this requirement. We provided students who were interested in this option with a letter verifying their attendance. This served as an important incentive for adolescents, in particular, those who were in alternative programs.

Providing participant compensation was another strategy used in this study. All students received a T-shirt with the study logo. They were also compensated up to $\$ 100$ for participating: $\$ 40$ after completing the 2-day interventions; $\$ 20$ for each of the 3-, and 6month follow-ups; and $\$ 30$ for the 12-month follow-up.

Retention. We utilized a number of retention strategies that had been used in similar studies (Jemmott, Jemmott, \& Fong, 1998; Jemmott, Jemmott, \& McCaffree, 1995). As part of the registration process for the interventions, participants were asked to provide contact information, including their address and phone number. Participants were also asked to provide contact information (name, address, phone number) for a responsible adult who did not live with them but who would be able to contact the participant. To maintain interest in the study over the 12-month period, birthday and holiday cards with the study logo were also sent to students.

Prior to the follow-up sessions, reminder cards were mailed to the addresses provided by the participants. Students were also contacted by phone 1 to 2 days before the follow-up session to remind them of the times and locations of the interventions. Those participants who did not attend the follow-up sessions were sent postcards, informing them of the next makeup or "straggler" session. These numerous "straggler" sessions were conducted in schools and other convenient locations. These special follow-ups often included only 1 to 3 students per session and were offered to provide the most flexibility to study participants to enhance participation.

A key retention strategy was the use of consistent personnel in contacting and administering questionnaires. Consistent staff, including a bilingual retention specialist, had responsibility for contacting adolescents or their families over the course of the study and in administering questionnaires at the follow-up or straggler sessions. This consistent contact enabled adolescents and their families to make a connection or develop confianza with one member of the study team. It also allowed the study team to understand how to facilitate continued participation in the study for individual adolescents.

\section{Adolescent Perceptions of Barriers and Facilitators to Participation}

As noted previously, there was a considerable drop in participants from the post-test to the 3-month followup. For students who were randomized into the HIV risk-reduction intervention, $82 \%$ completed the 3-month follow-up, while $86 \%$ of students in the general health promotion group completed the 3-month follow-up.

In an effort to understand the decline from post-test to the 3-month follow-up, a series of five questions were added to the follow-up questionnaires: (a) What are some of the reasons you come to the follow-up sessions? (b) What makes it hard for you to participate in the follow-up sessions? (c) What makes it easy to participate in the follow-up sessions? (d) What are reasons other students DO NOT participate? (e) What can we do to make it easier for you and other students to participate? Participants were given space to respond to each open-ended question.

For this analysis, a random selection of 106 respondents (46 male, 60 female students) were selected from the 3-month follow-up. Of these, 95 answered the questions in English, while 11 answered the questions in Spanish. The complete responses were copied verbatim. Spanish responses were first translated verbatim and subsequently analyzed. The data set was analyzed 


\section{Recruitment and Retention of Latino Adolescents to a Research Study}

through content analysis, with similar responses to each question grouped into general categories. The frequency of these general responses was evaluated, and representative statements and specific comments were highlighted. No significant differences were found between responses given by male and female participants in this study.

When examining the reasons students gave for coming to the follow-up sessions, four main patterns emerged: (a) peer influences and family encouragement, (b) program incentives, (c) commitment to parents and/ or friends, and (d) desire to help peers and family. First, peer influences, family encouragement, and the ability to pass knowledge onto friends and younger siblings were influential in participants' decisions to attend the follow-up.

"(I come to) talk to my friends, meet new people."

"My boyfriend encourages me to come; he brings me with him."

"My mom encourages me."

"It is easy ... to teach other students or to my little brothers and sisters."

Program incentives were also cited as a reason to continue participation.

"Because ... you get credit; get to meet people."

"For the credit for school; money."

"The money; see my friends...."

Adolescents also cited commitment to parents, friends, or school as a motive to continue to participate.

"Because I made the commitment to come; it's a good program."

"My friend ... comes."

"(Because) of school, parents, teachers."

Adolescents also indicated they participated as a way of learning and being prepared. Adolescents often cited the desire to help peers and others in their family as a reason for participating.

"I come to learn about stuff that I did not know like STDs; I didn't come for the money."

"To learn more about viruses of HIV and AIDS; to know how one should be prepared to have relations with my partner."
"It's a good way of learning; I give information to people."

A number of barriers to participation in the followup sessions were also identified by adolescents. These barriers included access and conflicts with other commitments such as work, jobs, school homework, extracurricular activities, and child care responsibilities. In addition, features of the questionnaire sessions were also cited as problematic. Adolescents indicated the questions were embarrassing, seemed repetitive, and were "hard." In addition, not having friends with them or being supported to participate in the programs by parents was also seen as a barrier.

When asked what made it easy to participate in the follow-up sessions, students identified personal support as the reason given most often. Students cited support from friends, supportive others (teachers, parents, relatives), and contact from program staff as reasons for continued participation.

"My mom encourages me."

"I [am] with my age group."

"You're constantly reminding us: phone/letters, etc."

"I know they (project staff) are really paying attention to me."

Finally, students identified four main suggestions for facilitating participation in follow-ups: (a) incentives, (b) program start times, (c) continued contact with project staff, and (d) increasing interactive components of the follow-up. Participants cited incentives-including more money and school credit for participation-as useful in increasing participation. Because the sessions were held on Saturday mornings, students indicated that starting later might be useful. Students liked the contact with project staff and requested more reminders, whether they were phone calls or reminders in schools. It was evident that students liked the interactive nature of the intervention and saw that as an element that should be included in future follow-ups, in addition to the questionnaires. Participants also felt that they could play a role in influencing their peers to attend.

Based on suggestions from participants, start times for the follow-up sessions were moved a half hour later 
in the morning, and the reimbursement for attendance at the 12-month follow-up was increased from $\$ 20$ to $\$ 30$.

\section{Discussion}

This study addresses many barriers and facilitators to participation in a randomized controlled trial designed for Latino adolescents. A vast majority of those sampled indicated no barriers to participation. However, based on participant survey answers, the most common barriers to participation included jobs or busy schedules; program issues, such as the timing of the follow-up or length of time spent filling out the questionnaire; and personal reasons, such as shyness or embarrassment while discussing sexual health and lack of friends or peer presence. Monetary compensation, or the perceived amount of it, was not mentioned as a barrier by anyone in this sample.

Major facilitators to participation included positive peer and family influences; program incentives such as money, school credit, and spending time with friends; commitment; and personal gain. Interestingly, the location and timing of the intervention and follow-up sessions were specified as facilitators to program participation as well as barriers.

There are several implications or lessons learned from this study that can be applied to future clinical trials for Latino adolescents. First, attention to building an infrastructure for recruitment and retention that incorporates the values of the community and population being served is critical. These components include community, school, and family endorsement and involvement throughout the study. Foundational to this study is building a research team that is able to understand the rigors involved in a research study (i.e., adherence to protocol, ethical and human subject issues). However, also as important is a team that is able to communicate and incorporate important values of the target population-in this instance, respeto-or respect for both the adolescents and parents.

One important lesson learned from this study is that the lives of Latino adolescents are complex.
Adolescents were busy not only with school and their own lives but with supporting their families, either by work or child care. At the beginning of the study, we had not anticipated the need to provide child care for children under the care of adolescent participants. Further, we were surprised by the mobility of adolescents and their families, especially among those who were predominantly Spanish speaking. A question to include in future studies might be to ask families about their intentions to remain in the area for the length of the study.

\section{How Do I Apply This Information to Nursing Practice?}

The results of this report are very encouraging for a number of reasons. The myth that "Latinos won't participate in research" or "Latino parents won't let their children participate in studies related to sex" was not supported by our experience. Efforts to inform and involve the community and in hearing and understanding concerns for their children facilitated the development of trust-or confianza-in the project and the research team. The desire to learn new knowledge and skills required to be healthy, as expressed by many adolescents, exemplifies an intrinsic motivator that can be incorporated into study designs. Further, adolescents indicated the desire to share what was learned with peers and other family members-a good illustration of the concept of familialism. The importance of both peer and family influences on adolescent health behaviors presents a potentially useful tool to incorporate in recruitment and retention strategies. In addition, seeking adolescent input prior to and during a study, might be useful in dealing with issues not anticipated at the onset of the study. Efforts at recruitment and retention of adolescents, in particular Latino adolescents, require extensive and targeted strategies. These efforts are necessary in order to ensure not only scientific rigor, but ultimately, to facilitate the research needed to base practice with this important population. 


\section{Recruitment and Retention of Latino Adolescents to a Research Study}

\section{References}

Broome, M.E., \& Richards, D.J. (2003). The influence of relationships on children's and adolescents participation in research. Nursing Research, 52(3), 191-197.

Clark-Jones, F., \& Broome, M.E. (2001). Focus groups with African American adolescents: Enhancing recruitment and retention in intervention studies. Journal of Pediatric Nursing, 16(2), 88-96.

Davis, L.L., Broome, M.E., \& Cox, R.P. (2002). Maximizing retention in community-based clinical trials. Journal of Nursing Scholarship, 34(1), 47-53.

Jemmott, J.B. III, Jemmott, L.S., \& Fong, G.T. (1998). A randomized controlled trial of abstinence and safer sex HIV risk-reduction interventions for young African American adolescents. Journal of the American Medical Association, 279(19), 1529-36.

Jemmott, L.S., Jemmott, J.B. III., \& McCaffree, K. (1995). Be proud! Be responsible! Strategies to empower youth to reduce their risk for AIDS. New York: Select Media.

Keller, C.S., Gonzales, A., \& Fleuriet, K.J. (2005). Retention of minority participants in clinical research studies. Western Journal of Nursing Research, 27(3), 292-306.

Lamb, J., Puskar, K.R., \& Tusaie-Mumford, K. (2001). Adolescent research recruitment issues and strategies: Application in a rural school setting. Journal of Pediatric Nursing, 16(1), 43-52.
Levkoff, S.E., Prohaska, T.R., Weitzman, P.F., \& Ory, M.G. (Eds.). (2000). Recruitment and retention in minority populations. New York: Springer.

McQuiston, C., \& Flaskerud, J.H. (2003). "If they don't ask about condoms, I just tell them." A descriptive case study of Latino lay health advisers' helping activities. Health Education and Behavior, 30(1), 79-96.

Pletsch, P.K., Howe, C., \& Tenney, M. (1995). Recruitment of minority subjects for intervention research. Image- the Journal of Nursing Scholarship, 27(3), 211-215.

Prado, G., Pantin, H., Schwartz, S.J., Lupei, N.S., \& Szapocznik, J. (2005). Predictors of engagement \& retention into a parentcentered, ecodevelopmental HIV preventive intervention for Hispanic adolescents and their families. Advanced Access published 7/27/05, Journal of Pediatric Psychology. Retrieved from http:// jpepsy.oxfordjournals.org/cgi/content/abstract/jsj046v1

Talashek, M.L., Norr, K.F., \& Dancy, B.L. (2003). Building teen power for sexual health. Journal of Transcultural Nursing, 14(3), 207-216.

Villarruel, A.M., Jemmott, L.S., \& Jemmott, J.B. III (2005). Designing a culturally based intervention to reduce HIV sexual risk for Latino adolescents. Journal of the Association of Nurses in AIDS Care, 16(2), 23-31.

Villarruel, A.M., Jemmott, J.B. III, \& Jemmott, L.S. (2006). A randomized controlled trial testing an HIV prevention intervention for Latino youth. Archives of Pediatric and Adolescent Medicine, 160 772-777. 